\title{
Effects of cola intake on fertility: a review
}

\author{
Atsushi Imai ${ }^{1 *}$, Satoshi Ichigo ${ }^{2}$, Hiroshi Takagi ${ }^{2}$, Kazutoshi Matsunami $^{2}$, Noriko Suzuki ${ }^{3}$, \\ Akio Yamamoto ${ }^{3}$ \\ ${ }^{1}$ Institute of Endocrine-Related Cancer, Matsunami General Hospital, Gifu, Japan; \\ ${ }^{*}$ Corresponding Author: aimai@matsunami-hsp.or.jp \\ ${ }^{2}$ Department of Obstetrics and Gynecology, Matsunami General Hospital, Gifu, Japan \\ ${ }^{3}$ Department of Obstetrics and Gynecology, Gifu University School of Medicine, Gifu, Japan
}

Received 22 June 2010; revised 12 July 2010; accepted 14 July 2010.

\begin{abstract}
The consumption of soft drinks has increased considerably during the last decades. Among them, the cola-based preparations are possibly the refreshments with the largest sales worldwide. During the previous years, important concerns have been raised about the effects of colas on human health. In this review, we introduce the cola effects on reproduction including pregnancy miscarriages, ovulatory and menstrual disorders, and reduced semen quality. Although caffeine intoxication may be thought to play the most important role, a component of cola other than caffeine, or in combination with caffeine, may be associated with increased risk of reproductive hazards in heavy cola $(>1 \mathrm{~L}$ per day)-consumers. Cola discontinuation usually leads to an uneventful recovery in the most cases suggesting justification of limitations in the maximum recommended daily dose of these soft drinks. Cola is not an essential beverage, and abstaining from drinking more than $1 \mathrm{~L}$ per day is a minor intrusion in one's personal life. Despite these uncertainties, this growing knowledge may alarm the fertility risk of chronic cola intake in peoples of childbearing age.
\end{abstract}

Keywords: Cola; Soft Drink; Caffeine; Semen; Miscarriage; Ovulation

\section{INTRODUCTION}

The consumption of soft drinks has increased considerable during the last decades. Among them, the colabased preparations are possibly the refreshments with the largest sale worldwide. During the previous years, important concerns have been raised about the effects of colas on human health. In addition to the possible detri- mental effects of chronic cola consumption (enamel softening [1,2], bone demineralization [3,4], hypokalemic myopathy [5-7], development of metabolic syndrome and diabetes mellitus [8-10], and chronic kidney diseases $[11,12])$, several lines of evidence suggest that the chronic consumption of large amounts of cola-based soft drinks may increase the risk of reproductive problems such as decreased fetal growth, preterm delivery, and spontaneous abortion [13-16]. However, results from these epidemiological studies suggesting the association between cola consumption and such outcomes have been conflicting and the available information is incomplete and remains controversial. The observations may have important public health implications as, recently, trends of increasing the portion size of these preparations have been noticed. With the aim of evaluating the available epidemiological evidence of the effect of cola consumption on reproductive quality (see Table 1), a systematic qualitative review was conductive.

\section{PHARMACOLOGICAL EFFECTS OF INGREDIENTS IN COLA}

Cola contains many different chemical compounds and no certainty exists as to which ones may be associated with disease risk.

Cola soft drinks may contain large amounts of glucose (up to $11 \mathrm{~g}$ of sugar/dL) and high-fructose corn syrup. Highly caloric carbonated soft drinks are often sweetened with high fructose corn syrup, which makes soda inexpensive to produce. While sugary soda may be sold cheaply as a food item and yield a profit, they provide little satiety. Thus, the excessive consumption of theses preparations may lead to glycemic load, resulting in osmotic diuresis and hyperinsulinemia. Fructose itself may cause kidney damage, perhaps mediated by uric acid [17].

Cola contains sufficient amounts of caffeine ranging 
Table 1. Main points of the cola (carbonated soft drink) - induced reproductive hazards.

\begin{tabular}{|c|c|c|c|}
\hline Outcomes & $\begin{array}{l}\text { Amount of cola } \\
\text { consumption* }\end{array}$ & $\begin{array}{l}\text { Suggested } \\
\text { cause }\end{array}$ & Refs. \\
\hline $\begin{array}{l}\text { Reduced sperm } \\
\text { count ( } 30 \% \text { below } \\
\text { the average in } \\
\text { non-cola-drinkers) }\end{array}$ & $\begin{array}{l}>1 \mathrm{~L} \text { per day } \\
\text { during the past } \\
\text { week }\end{array}$ & $\begin{array}{l}\text { Constituents } \\
\text { in cola other } \\
\text { than caffeine }\end{array}$ & [33] \\
\hline $\begin{array}{l}\text { Ovulatory disor- } \\
\text { der infertility }\end{array}$ & $\begin{array}{c}>2 \text { soft drinks a } \\
\text { day }\end{array}$ & $\begin{array}{l}\text { Contents in } \\
\text { cola other } \\
\text { than caffeine } \\
\text { or sugar }\end{array}$ & [30] \\
\hline $\begin{array}{l}\text { Shortened menses } \\
\text { duration and cycle }\end{array}$ & $\begin{array}{c}>300 \mathrm{mg} \text { of } \\
\text { caffeine per day }\end{array}$ & Caffeine & [21] \\
\hline $\begin{array}{l}\text { Increased risk of } \\
\text { miscarriage (haz- } \\
\text { ard ratio of } 2.23 \text { ) }\end{array}$ & $\begin{array}{l}200 \mathrm{mg} \text { of caf- } \\
\text { feine per day } \\
\text { during pregnancy }\end{array}$ & Caffeine & {$[45,50]$} \\
\hline
\end{tabular}

*Assumed caffeine content of $150 \mathrm{mg} / \mathrm{L}$.

from 95 to $160 \mathrm{mg} / \mathrm{L}$. Caffeine, 1,3,7-trimethylxanthine, is among the most frequently ingested pharmacologically active substances $[18,19]$. Carbonated soft drinks and coffee are the main sources of caffeine intake.

Other components in cola, such as phosphorus in dark cola, may reveal significant physiological actions.

\section{OVULATION AND MENSTRUATION DISOERDERS}

Women who consume caffeine may be less likely to have long menses. This phenomena is biologically likely plausible because caffeine is a known vasoconstrictor [20], reducing uterine blood flow. Constriction of uterine blood vessels would be expected to reduce uterine blood flow, which could reduce menstrual bleeding and shorten the duration of menses [21]. Caffeine may alter the duration of menstrual cycle via the effect of caffeine on sex hormones or the hormone receptors [22]. However, the results of studies of caffeinated beverage consumption in relation to fecundity are inconsistent. Several studies in humans have reported an association between caffeine intake and delayed time to conception [23-26], in contrast, others have shown either no association $[27,28]$ or a relation only at very high levels of intake [29]. Most of these studies have retrospectively collected information on alcohol and caffeine intake, making the results susceptible to biases. The study by Fenster et al. [21] described the relation between caffeine intake and menstrual function was examined in 403 healthy premenopausal women who belonged to Kaiser Permanente Medical Care Program in 1990-1991. They collected information about caffeinated beverage intake as well as other lifestyle, demographic, occupational, and environmental factors. Subjects collected daily urine samples and completed a daily diary for an average of five menstrual cycles. Caffeine intake was not strongly related to an increased risk for anovulation, short luteal phase, long follicular phase, long cycle, or measures of withinwoman cycle variability. Chavarro et al. [30] followed 18,555 married women without a history of infertility for 8 years as they attempted to become (or became) pregnant. Soft drinks were the only beverages positively related to ovulatory infertility. Intake of caffeinated soft drinks was associated with a higher risk of ovulatory disorder infertility among women consuming at least 2 or more soft drinks per day. Women consuming 2 or more caffeinated soft drinks per day had a $47 \%$ greater risk of ovulatory infertility than women who consumed less than 1 caffeinated soft drink per week. Their analyses suggested that neither caffeine nor fructose was responsible for this association. Extreme comparisons of caffeine and coffee intake suggested no association or an inverse association with ovulatory disorder infertility. Some constituents in cola other than caffeine or sugar may cause ovulatory disorder.

Regarding the risk of ovarian cancer developments, laboratory data suggest that caffeine or some components of coffee may cause DNA mutations and inhibit tumor suppressor mechanisms, leading to neoplastic growth. An increased risk was observed in the multivariate model for women who reported drinking five or more cups/day of caffeinated coffee compared to women who reported drinking none. Decaffeinated coffee, total coffee, and caffeine were not statistically significantly associated with ovarian cancer incidence. A component of coffee other than caffeine, or in combination with caffeine, may be associated with increased risk of ovarian cancer in postmenopausal women who drink five or more cups of coffee a day [31].

\section{SEMEN QUALITY DECLINE}

A recent Danish study revealed that sperm counts are lower in men who drink cola of $1 \mathrm{~L}$ (estimated to contain $100-140 \mathrm{mg}$ of caffeine) or more per day, averaging $31 \%$ below the average in control $[32,33]$. This cola's effect on sperm seems not to be attributable to their caffeine content; caffeine intake of $<800 \mathrm{mg}$ per day and cola consumption of $<140.5$-L bottles per week is not associated with reduced semen quality. The reduction in semen quality among high-quantity cola drinkers must be attributed to constituents in cola other than caffeine because the caffeine content of cola is not high. They also added that although the cola drinkers' sperm count was still within the normal range, at 35 million $/ \mathrm{mL}$, cola might nonetheless dampen their fertility [33]. Among the study participants, those not drinking cola had an aver- 
age count of $50 \mathrm{million} / \mathrm{mL}$.

In fact, previous studies on caffeine intake and sperm quality have been contradictory [34-36]. Alternatively, these associations may be attributed to the less healthy lifestyle and diet of high-quantity consumers. Heavy quantity consumers of cola or caffeine had an unhealthier lifestyle, which has previously been associated with poorer semen quality [37-40]. To the extent possible, many researchers considered these factors in the analyses, and they did not appear to explain the caffeine and cola associations. High-quantity caffeine and cola consumers also had a less healthy diet, and previous studies have found reduced semen quality among men who consumed few fruits and vegetables and had a low intake of antioxidant and trace minerals [33]. Cola contains sufficient amounts of many minerals including phosphorus.

High cola and caffeine consumption may be related to in utero exposure to caffeine. Ramlau-Hansen et al. [41] studied the association between prenatal coffee and current caffeine exposure and semen quality. There is a tendency toward decreasing crude median semen volume and adjusted mean testosterone and inhibin concentrations with increasing maternal coffee consumption during pregnancy. Sons of mothers drinking 4-7 cups/day had lower testosterone levels than sons of mothers drinking 0-3 cups/day. However caffeine intake had no impact on semen quality.

\section{MISCARRIAGES}

Caffeine can readily cross the placental barrier to the fetus [42]; its clearance is prolonged in pregnant women, and its metabolism rate is low in the fetus because of low levels of enzymes $[43,44]$. It may also influence cell development through increasing cellular cyclic adenosine monophosphate (cAMP) concentrations and decrease intervillous placental blood flow via increasing circulating catecholamines $[18,19,45]$. Caffeine intake during pregnancy has been suggested as a risk factor for adverse reproductive outcomes. Therefore, caffeine could have an adverse effect on fetal development. Indeed, caffeine intake has been reported to increase the risk of miscarriage [15,16,46-48]. Although numerous studies on maternal caffeine consumption and the risk of miscarriage have been published since the 1980s, the effect of caffeine intake on the risk of miscarriage remains controversial because of methodological limitations in past studies. Many studies have relied on retrospective information, which is subject to recall bias [15,16,46-48]. Some had only a small number of participants, which limited their power to detect an effect. Some did not take into account potential confounding factors such as smok- ing, alcohol consumption, and most importantly, pregnancy-related symptoms including nausea and vomiting. Some recruited women who sought prenatal care at their 13th to 28th weeks of gestation, therefore too late in pregnancy to study miscarriage. Such controversy has led to the uncertainty about the health effects of caffeine consumption during pregnancy among both clinicians and pregnant women alike.

Weng et al. [45] demonstrated, in their prospective cohort study, an elevated risk of miscarriage associated with caffeine consumption during pregnancy and a doseresponse relationship with most of the risk associated with caffeine consumption at $200 \mathrm{mg}$ (which approximately $1.5 \mathrm{~L}$ cola contains) or greater per day. This observed effect was independent of many potential confounders including pregnancy related symptoms such as nausea, vomiting, and aversion to caffeine consumption. Even among women who never changed caffeine consumption pattern during pregnancy, there was an almost $80 \%$ increased risk of miscarriage associated with caffeine consumption of $200 \mathrm{mg}$ /day or greater, although it was not statistically significant because of reduced sample size by stratification. The increased risk of miscarriage appeared to be due to caffeine itself rather than other possible chemicals in coffee because caffeine intake from noncoffee sources showed the similarly increased risk of miscarriage. On the other hand, a similar cohort study, published same month, by Svavitz et al. [49] demonstrated that this can result in recall bias generating a positive results, whereas when caffeine exposure is ascertained before miscarriage, the findings indicate no effect of caffeine. To data, the literature is still inconclusive regarding the influence of caffeine on miscarriage and the available information is incomplete and remains controversial $[47,50]$.

\section{CONCLUSIONS}

Although much epidemiological work has been conducted, results from studies investigating the association between cola consumption and outcomes such as reproductive hazards have been conflicting and the available information was incomplete and remained controversial. As summarized in Table 1, our reviewing recent reports suggest the association between cola consumption and increased risk of reproductive hazards. In addition to caffeine, cola contains a number of other chemical compounds, and one or more of these could be physiologically active. Further studies might attempt to disentangle a caffeine effect from a noncaffeine effect by comparing different types of beverage drinkers. Cola is not an essential beverage, and abstaining from drinking more than $1 \mathrm{~L}$ per day is a minor intrusion in one's personal life. 
The growing knowledge may alarm the fertility risk of chronic cola intake in peoples of childbearing age.

Authors contributions: All authors discussed and wrote the draft of the manuscript, and A.I. coordinated the project and wrote the final version.

Conflict of interest statement: The authors report no conflicts of interest.

\section{REFERENCES}

[1] Jensdottir, T., Arnadottir, I., Thorsdottir, I. and Holbrook, W.P. (2004) Relationship between dental erosion, soft drink consumption, and gastroesophageal reflux among Icelanders. Clinical Oral Investigation, 8(2), 91-96.

[2] Jensdottir, T., Holbrook, P., Nauntofte, B., Buchwald, C. and Bardow, A. (2006) Immediate erosive potential of cola drinks and orange juices. Journal of Dental Research, 85(3), 226-230.

[3] Tucker, K. (2009) Osteoporosis prevention and nutrition. Current of Osteoporosis Reports, 7(4), 111-117.

[4] Ogur, R., Uysal, B., Ogur, T., Yaman, H., Oztas, E., Ozdemir, A. and Hasde, M. (2007) Evaluation of the effect of cola drinks on bone mineral density and associated factors. Basic and Clinical Pharmacology and Toxicology, 100(5), 334-338.

[5] Matsunami, K. and Imai, A. (1994) Hypokalemia in a pregnant woman with long-term heavy cola consumption. International Journal of Gynaecology and Obstetrics, 44(3), 283-284.

[6] Tsimihodimos, V., Kakaidi, V. and Elisaf, M. (2009) Cola-induced hypokalaemia: Pathophysiological mechanisms and clinical implications. International Journal of Clinical Practice, 63(6), 900-902.

[7] Packer, C. (2009) Cola-induced hypokalaemia: A supersized problem. International Journal of Clinical Practice, 63(6), 833-835.

[8] Shoham, D., Durazo-Arvizu, R., Kramer, H., Luke, A., Vupputuri, S., Kshirsagar, A. and Cooper, R.S. (2008) Sugary soda consumption and albuminuria: Results from the National Health and Nutrition Examination Survey, 1999-2004. PLoS One, 3(10), e3431.

[9] Assy, N., Nasser, G., Kamayse, I., Nseir, W., Beniashvili, Z., Djibre, A. and Grosovski, M. (2008) Soft drink consumption linked with fatty liver in the absence of traditional risk factors. Canadian Journal of Gastroenterology, 22(10), 811-813.

[10] Acheson, K. (2005) Caffeine and insulin sensitivity. Metabolic Syndrome \& Related Disorders, 3(1), 19-25.

[11] Paganini-Hill, A., Kawas, C. and Corrada, M. (2007) Non-alcoholic beverage and caffeine consumption and mortality: The Leisure World Cohort Study. Preventive Medicine, 44(4), 305-310.

[12] Saldana, T., Basso, O., Darden, R. and Sandler, D. (2007) Carbonated beverages and chronic kidney disease. Epidemiology, 18(4), 501-506.

[13] Bech, B., Nohr, E., Vaeth, M., Henriksen, T. and Olsen, J. (2005) Coffee and fetal death: A cohort study with prospective data. American Journal of Epidemiology, 162(10), 983-990.

[14] Parazzini, F., Chatenoud, L., Di Cintio, E., Mezzopane,
R., Surace, M., Zanconato, G., Fedele, L. and Benzi, G. (1998) Coffee consumption and risk of hospitalized miscarriage before 12 weeks of gestation. Human Reproduction, 13(8), 2286-2291.

[15] Matijasevich, A., Santos, I. and Barros, F. (2005) Does caffeine consumption during pregnancy increase the risk of fetal mortality? A literature review. Cadernos de Saúde Pública, 21(6), 1676-1684.

[16] Signorello, L. and McLaughlin, J. (2004) Maternal caffeine consumption and spontaneous abortion: A review of the epidemiologic evidence. Epidemiology, 15(2), 229239.

[17] Johnson, R., Segal, M., Sautin, Y., Nakagawa, T., Feig, D.I., Kang, D.H., Gersch, M.S., Benner, S. and Sánchez-Lozada, L.G. (2007) Potential role of sugar (fructose) in the epidemic of hypertension, obesity and the metabolic syndrome, diabetes, kidney disease, and cardiovascular disease. American Journal of Clinical $\mathrm{Nu}$ trition, 86(4), 899-906.

[18] Arnaud, M. (1987) The pharmacology of caffeine. Progress in Drug Research, 31, 273-313.

[19] Benowitz, N. (1990) Clinical pharmacology of caffeine. Annual Reviews of Medicine, 41, 277-288.

[20] Chou, T. and Benowitz, N. (1994) Caffeine and coffee: Effects on health and cardiovascular disease. Comparative Biochemistry \& Physiology. Part C, Pharmacology, Toxicology \& Endocrinology, 109(2), 173-189.

[21] Fenster, L., Quale, C., Waller, K., Windham, G.C., Elkin, E.P., Benowitz, N. and Swan, S.H. (1999) Caffeine consumption and menstrual function. American Journal of Epidemiology, 149(6), 550-557.

[22] Kitts, D. (1987) Studies on the estrogenic activity of a coffee extract. Journal of Toxicology \& Environmental Health, 20(1-2), 37-49.

[23] Christianson, R., Oechsli, F. and van den Berg, B. (1989) Caffeinated beverages and decreased fertility. Lancet, 1(8634), 378-379.

[24] Grodstein, F., Goldman, M., Ryan, L. and Cramer, D. (1993) Relation of female infertility to consumption of caffeinated beverages. American Journal of Epidemiology, 137(12), 1353-1360.

[25] Stanton, C. and Gray, R. (1995) Effects of caffeine consumption on delayed conception. American Journal of Epidemiology, 142(12), 1322-1329.

[26] Bolúmar, F., Olsen, J., Rebagliato, M. and Bisanti, L. (1997) Caffeine intake and delayed conception: A European multicenter study on infertility and subfecundity. European study group on infertility subfecundity. American Journal of Epidemiology, 145(4), 324-334.

[27] Alderete, E., Eskenazi, B. and Sholtz, R. (1995) Effect of cigarette smoking and coffee drinking on time to conception. Epidemiology, 6(4), 403-408.

[28] Joesoef, M., Beral, V., Rolfs, R., Aral, S. and Cramer, D. (1990) Are caffeinated beverages risk factors for delayed conception? Lancet, 335(8682), 136-137.

[29] Jensen, T., Henriksen, T., Hjollund, N., Scheike, T., Kolstad, H., Giwercman, A., Ernst, E., Bonde, J.P., Skakkebaek, N.E. and Olsen, J. (1998) Caffeine intake and fecundability: A follow-up study among 430 Danish couples planning their first pregnancy. Reproductive Toxicology, 12(3), 289-295.

[30] Chavarro, J., Rich-Edwards, J., Rosner, B. and Willett, W. 
(2009) Caffeinated and alcoholic beverage intake in relation to ovulatory disorder infertility. Epidemiology, 20(3), 374-381.

[31] Lueth, N., Anderson, K., Harnack, L., Fulkerson, J. and Robien, K. (2008) Coffee and caffeine intake and the risk of ovarian cancer: The Iowa Women's Health Study. Cancer Causes \& Control, 19(10), 1365-1372.

[32] Endocrine Society (2010) Sperm and cola don't mix wee. EndocrineNews, May 2010, 27.

[33] Jensen, T., Swan, S., Skakkebaek, N., Rasmussen, S. and Jørgensen, N. (2010) Caffeine intake and semen quality in a population of 2,554 young Danish men. American Journal of Epidemiology, 171(8), 883-891.

[34] Vine, M., Setzer, R.J., Everson, R. and Wyrobek, A. (1997) Human sperm morphometry and smoking, caffeine, and alcohol consumption. Reproductive Toxicology, 11(2-3), 179-184.

[35] Marshburn, P., Sloan, C. and Hammond, M. (1989) Semen quality and association with coffee drinking, cigarette smoking, and ethanol consumption. Fertility and Sterility, 52(1), 162-165.

[36] (1997) Reproductive toxicology. Caffeine. Environmental Health Perspectives, 105(Suppl. 1), 1279-1280.

[37] Jensen, T., Jacobsen, R., Christensen, K., Nielsen, N. and Bostofte, E. (2009) Good semen quality and life expectancy: A cohort study of 43,277 men. American Journal of Epidemiology, 170(5), 559-565.

[38] Jensen, T., Jørgensen, N., Asklund, C., Carlsen, E., Kristensen, T.S., Holm, M. and Skakkebaek, N.E. (2007) Self-rated health and semen quality among 3,457 young Danish men. Fertility and Sterility, 88(5), 1366-1373.

[39] Ramlau-Hansen, C., Nohr, E., Thulstrup, A., Bonde, J., Storgaard, L. and Olsen, J. (2007) Is maternal obesity related to semen quality in the male offspring? A pilot study. Human Reproduction, 22(10), 2758-2762.

[40] Ramlau-Hansen, C., Thulstrup, A., Storgaard, L., Toft, G., Olsen, J. and Bonde, J. (2007) Is prenatal exposure to tobacco smoking a cause of poor semen quality? A fol- low-up study. American Journal of Epidemiology, 165 (12), 1372-1379.

[41] Ramlau-Hansen, C., Thulstrup, A., Bonde, J., Olsen, J. and Bech, B. (2008) Semen quality according to prenatal coffee and present caffeine exposure: Two decades of follow-up of a pregnancy cohort. Human Reproduction, 23(12), 2799-2805.

[42] Goldstein, A. and Warren, R. (1962) Passage of caffeine into human gonadal and fetal tissue. Biochemical Pharmacology, 11(2), 166-168.

[43] Aldridge, A., Aranda, J. and Neims, A. (1979) Caffeine metabolism in the newborn. Clinical Pharmacology and Therapeutics, 25(4), 447-453.

[44] Aldridge, A., Bailey, J. and Neims, A. (1981) The disposition of caffeine during and after pregnancy. Seminars in Perinatology, 5(4), 310-314.

[45] Weng, X., Odouli, R. and Li, D. (2008) Maternal caffeine consumption during pregnancy and the risk of miscarriage: A prospective cohort study. American Journal of Obstetrics and Gynecology, 198(3), e271-e278.

[46] Fernandes, O., Sabharwal, M., Smiley, T., Pastuszak, A., Koren, G. and Einarson, T. (1998) Moderate to heavy caffeine consumption during pregnancy and relationship to spontaneous abortion and abnormal fetal growth: A meta-analysis. Reproductive Toxicology, 12(4), 435-444.

[47] Signorello, L. and McLaughlin, J. (2008) Caffeine and miscarriage: Case closed? American Journal of Obstetrics and Gynecology, 199(5), e14-e15.

[48] Leviton, A. and Cowan, L. (2002) A review of the literature relating caffeine consumption by women to their risk of reproductive hazards. Food and Chemical Toxicology, 40(9), 1271-1310.

[49] Savitz, D., Chan, R., Herring, A., Howards, P. and Hartmann, K. (2008) Caffeine and miscarriage risk. Epidemiology, 19(1), 55-62.

[50] Graham, N., Hammond, C.J. and Gold, M. (2008) Caffeine in miscarriages: It's not just in the coffee. American Journal of Obstetrics and Gynecology, 199(5), e15. 